\title{
A APROPRIAÇÃO INDEVIDA DO JAMBU (Acmella oleracea) E AS INCONVENCIONALIDADES DO MARCO LEGAL DA BIODIVERSIDADE NO PROCESSO DE COLONIALISMO BIOCULTURAL
}

João Paulo Rocha de Miranda*

\section{RESUMO}

Este trabalho objetiva investigar o colonialismo biocultural dos conhecimentos tradicionais associados à biodiversidade e a compatibilidade ou não do marco legal da biodiversidade com os tratados internacionais. Para tanto, é analisado o caso das patentes do jambu (Acmella oleracea), hortaliça amazônica usada na culinária e na etnomedicina. Esta pesquisa é aplicada, quantitativa e qualitativa. $\mathrm{O}$ método é o dedutivo, partindo do colonialismo biocultural, passando pela apropriação do jambu, até chegar na inconvencionalidade da Lei 13.123/15. Assim, se demonstra que as patentes do jambu são incompatíveis com as normas brasileiras e internacionais e que o marco legal da biodiversidade é inconvencional.

Palavras-chave: Jambu. Acmella oleracea. Inconvencionalidade. Colonialismo biocultural. Marco legal da biodiversidade.

\section{THE IMPROVED APPROPRIATION OF JAMBU (Acmella oleracea) AND THE INCONVENTIONALITIES OF THE LEGAL FRAMEWORK OF BIODIVERSITY IN THE PROCESS OF BIOCULTURAL COLONIALISM}

\begin{abstract}
This work aims to investigate the biocultural colonialism of the traditional knowledge associated to biodiversity and the compatibility or not of the legal framework of biodiversity with international treaties. To do so, the case of the jambu (Acmellaoleracea), Amazonian vegetable used in cooking and ethnomedicine is analyzed. This research is applied, quantitative and qualitative. The method is deductive, starting from biocultural colonialism, passing through the appropriation of the jambu, until arriving at the unconventionality of Law 13123/15. Thus, it is demonstrated that jambu patents are incompatible with Brazilian and international standards and that the legal framework of biodiversity is unconventional.
\end{abstract}

Keywords: Jambu. Acmella oleracea. Inconventionalities Biocultural Colonialism. Legal framework of biodiversity.

\footnotetext{
* Professor Adjunto de Direito Ambiental da Universidade Federal de Mato Grosso, Campus Universitário do Araguaia. Doutor em Direitos Humanos e Meio Ambiente pela UFPA. Mestre em Direito Agroambiental pela UFMT. Líder do Grupo de Pesquisa Direitos Humanos, Biodiversidade e Empregos Verdes - UFMT/CNPq. End. Postal: Av. Valdon Varjão, no 6390, Campus II UFMT/CUA, Barra do Garças-MT, Cep 78.600-000. E-mail: jpr.miranda@gmail.com
}

Revista de Direito Ambiental e Socioambientalismo | e-ISSN: 2525-9628 | Porto Alegre | v. 4 | n. 2 | 


\section{INTRODUÇÃO}

O presente estudo visa investigar o colonialismo biocultural dos conhecimentos tradicionais associados à biodiversidade e da própria diversidade biológica, bem como a tentativa de legitimação deste no Brasil, através de uma norma flagrantemente inconvencional. Para tanto, o colonialismo biocultural será analisado a partir do caso do jambu (Acmella oleracea) uma espécie de planta amazônica, popularmente conhecida como agrião do Pará, muito utilizada na culinária da região Norte do País, principalmente no Pará, em pratos famosos como o tacacá e o pato no tucupi. Além disso, esta planta é usada pelos povos indígenas e ribeirinhos como analgésico, anestésico fungicida e carrapaticida.

A fim de atender este objetivo, esta pesquisa é aplicada, quantitativa no aspecto ao número de patentes do jambu, e qualitativa, na análise do fenômeno do colonialismo biocultural. Já quanto ao método, esta investigação adota o dedutivo, partindo a pesquisa bibliográfica da conjuntura geral do colonialismo biocultural até o caso concreto e específico do jambu. Já no que se refere à apropriação patentária do jambu, será evidenciado o colonialismo biocultural a partir do levantamento mundial das patentes referentes ao jambu, por meio do método de análise de conteúdo por traços de significação. Tal procedimento será útil para demonstrar e exemplificar que a apropriação da biodiversidade e dos conhecimentos tradicionais associados é instrumentalizada pelo direito de propriedade industrial.

A partir disso, será demonstrado como o Estado brasileiro procurou realizar a legitimação do colonialismo biocultural, regulamentando o acesso e uso do patrimônio genético da biodiversidade e dos conhecimentos tradicionais, que passou a ser regido no Brasil pela Lei n. ${ }^{o} 13.123 / 15$, regulamentada pelo Decreto n. ${ }^{o} 8772 / 16$, declarado pelo governo brasileiro como o novo marco legal da biodiversidade. Isto configurou num procedimento de alteração radical do sistema então vigente consubstanciado na Medida Provisória 2.186-16/01, que apesar de possuir diversas falhas assegurava direitos essenciais como o consentimento prévio e repartição de benefícios em todas as hipóteses de acesso e uso. Todavia, a nova legislação, atendendo aos apelos dos setores industriais buscou estruturar um sistema de isenções que deixou desprotegidos os povos e comunidades tradicionais, além de representar uma flagrante violação dos direitos humanos estabelecidos nos Tratados Interacionais afetos ao tema.

Nesta análise, teremos como foco principal o cenário de disputa dos recursos genéticos e dos conhecimentos tradicionais associados à biodiversidade. Este culmina com a colisão de normas internacionais que incidem sobre o tema, como a Convenção da Diversidade Biológica

Revista de Direito Ambiental e Socioambientalismo | e-ISSN: 2525-9628 | Porto Alegre | v. 4 | n. 2 |

p. $01-18$ | Jul/Dez. 2018 


\section{A APROPRIAÇÃO INDEVIDA DO JAMBU (Acmella oleracea) E AS \\ INCONVENCIONALIDADES DO MARCO LEGAL DA BIODIVERSIDADE NO PROCESSO DE \\ COLONIALISMO BIOCULTURAL}

(CDB) e a Convenção 169 da OIT , com o marco legal da biodiversidade brasileira. Destarte, pode-se afirmar que a Lei 13.123/15 tentou suprimir tais direitos em relação a algumas atividades que envolvam a biodiversidade e os conhecimentos tradicionais. Todavia, esta supressão não se sustenta no sistema jurídico pátrio, diante da supralegalidade dos tratados internacionais de Direitos Humanos.

\section{O NOVO COLONIALISMO DO SUL SOCIOLÓGICO}

No capitalismo contemporâneo o "biocolonialismo [...] traduzem [...] o paradigma pós-moderno no que se refere aos avanços da engenharia genética e seus impactos na humanidade [...]" (OLIVEIRA, 2012, p.149). Assim, este fenômeno pode ser entendido como a apropriação indevida de recursos biológicos dos países em desenvolvimento e ricos em biodiversidade pelos países que dominam os processos biotecnológicos mais modernos e sediam grandes corporações industriais de engenharia genética (MORIN, 2004), voltadas principalmente para os setores farmacêuticos e do agronegócio. É, portanto, uma nova forma de colonialismo, chamado nesta tese de colonialismo biocultural, para ressaltar que a apropriação indevida é da biodiversidade juntamente com os conhecimentos tradicionais a ela associada, devido a indissociabilidade destes elementos. Desta forma, os países, do que chamamos aqui de norte sociológico, fomentam um processo de colonização do patrimônio genético, dos conhecimentos tradicionais associados à biodiversidade e dos recursos naturais, sociais e culturais dos países do sul sociológico.

Neste momento, é importante esclarecer que a ideia de norte e sul sociológicos é inspirada na noção de norte e sul global. Cunhada por Boaventura de Sousa Santos, este define que norte global é formado pelos Estados Unidos da América, Europa, Austrália e Nova Zelândia; enquanto o sul global coincide com o geográfico, sendo formado pela África, América do Sul e Ásia (SANTOS, 1995, p.508). Assim, o que caracteriza a relação norte-sul global é justamente o aspecto colonial de exploração e dominação, que persiste até os dias de hoje. Portanto, isto é reflexo do capitalismo e do seu modelo neoliberal, que hierarquiza os saberes, bem como os sistemas biológicos, econômicos e políticos, em um processo apelidado de colonialidade do poder (MENESES, 2008, p.5-10), novo colonialismo (MIRANDA; XAVIER, 2013, p.199), biocolonialismo (SHIVA, 2005, p.330) ou colonialismo biocultural. Assim, o projeto imperial do Norte Global para o Sul Global é uma metáfora da exploração e exclusão social, motivo pelo qual se utiliza aqui o termo norte e sul sociológicos.

Revista de Direito Ambiental e Socioambientalismo | e-ISSN: 2525-9628 | Porto Alegre | v. 4 | n. 2

p. $01-18$ | Jul/Dez. 2018 
Desta forma, o colonialismo biocultural se vincula a relações de poder e de mercado.

Assim, “[...] o que ocorre com a biodiversidade no atual sistema internacional de patentes [...]"(MANDRAZO, 2011, p.28), é justamente o colonialismo biocultural, que “[...] se assemelha melhor ao colonialismo, em que os poderes dominantes se apropriam dos recursos dos povos dominados e justificam esta apropriação em termos das suas próprias doutrinas jurídicas e políticas.” (MANDRAZO, 2011, p.28). Desta maneira, “a geopolítica desta relação polarizou os hemisférios - norte e sul: o primeiro mais pobre em biodiversidade, concentra as nações mais ricas em tecnologia; o segundo concentra os países mais bio e sociodiversos, porém com pouca tecnologia."(AZEVEDO; MOREIRA, 2005, p.44).

Contudo, ainda é necessário entender como ocorre “[...] a apropriação indébita por parte de grandes laboratórios farmacêuticos internacionais dos conhecimentos adquiridos por povos indígenas, quilombolas e outros, acerca das propriedades terapêuticas ou comerciais [...]"(FARIA, 2017) de elementos da biodiversidade, sejam de microrganismos, de fungos, da fauna e da flora “[...] de diversos países, ou de seus princípios ativos utilizados para a confecção de medicamentos." (FARIA, 2017).

Bem, existem varias formas escusas. Todas elas têm o mesmo modo operacional. Nacionais ou estrangeiros infiltrando-se em comunidades tradicionais ou em áreas indígenas para descobrirem seres vivos com interesse para as indústrias, principalmente farmacêuticas, agrícolas ou alimentares. Assim, coletam exemplares e descobrem, com o auxílio das comunidades tradicionais, seus usos e aplicações. Entretanto, estas comunidades não fornecem o consentimento prévio, pois, na maioria das vezes, nem sabem que o objetivo é uso comercial e/ou industrial dos seus conhecimentos tradicionais. Assim, de posse destas valiosas informações, voltam para seus países e utilizam as espécies e os conhecimentos dos povos indígenas e/ou comunidades tradicionais para isolarem os princípios ativos, que, uma vez descobertos são patenteados. Este processo confere-lhes o monopólio, por 20 (vinte) anos, da comercialização ou o direito de receberem um valor a cada vez que aquele produto for comercializado. Desta forma, comercializam o produto em escala mundial, inclusive para o país de origem do etnoconhecimento, sem repartir benefício algum com as comunidades tradicionais (LAVORATO, 200?, p.4).

Aqui faz necessário ressaltar que esta apropriação indevida dos conhecimentos tradicionais e da biodiversidade não é um processo exclusivo do setor farmacológico, embora seja o principal, mas abrange também o agropecuário e o alimentício. Contudo, “[...] a indústrias

Revista de Direito Ambiental e Socioambientalismo | e-ISSN: 2525-9628 | Porto Alegre | v. 4 | n. 2 |

p. $01-18$ | Jul/Dez. 2018 


\section{A APROPRIAÇÃO INDEVIDA DO JAMBU (Acmella oleracea) E AS \\ INCONVENCIONALIDADES DO MARCO LEGAL DA BIODIVERSIDADE NO PROCESSO DE \\ COLONIALISMO BIOCULTURAL}

farmacêuticas tornaram-se as maiores exploradoras do conhecimento medicinal tradicional para os principais produtos e com lucro, no mercado mundial anual, no valor de 43 bilhões de dólares" (POSEY, 1987, p.272).

Entretanto, é preciso frisar que até o milênio passado, não havia regulamentação no Brasil quanto ao acesso aos conhecimentos tradicionais associados ao patrimônio genético. Além disso, a biopirataria não estava, assim como ainda não está, tipificado no ordenamento jurídico penal brasileiro. Contudo, sempre foi um fato reprovado socialmente, com repercussões econômicas e socioambientais.

Talvez um dos primeiros casos emblemáticos registrados de biopirataria ou acesso indevido dos conhecimentos tradicionais associados e da própria biodiversidade que o Brasil tenha sofrido se refere ao contrabando inglês de sementes de seringueira (Hevea brasiliensis), árvore da qual se extrai o látex para a fabricação de borracha, que o Brasil dominou de 1850 a 1913, produzindo 95\% (noventa e cinco por cento) da borracha do mundo (JACKSON, 2011, p.10).

Assim, em 1876 o inglês Henry Hickham contrabandeou 70 (setenta) mil sementes de seringueira da Amazônia brasileira para o Jardim Botânico de Londres, da onde foram enviadas para as colônias inglesas na Índia e na Nova Zelândia. De forma que, “em 1913, a borracha produzida por 70 mil sementes contrabandeadas do Brasil e plantadas em seringais de cultivo asiáticos da Grã-Bretanha inundou o mercado, superando a venda da borracha selvagem, mais cara, e tirando-a de cena." (JACKSON, 2011, p.13).

Outro exemplo, bastante emblemático é a vacina do sapo. Na verdade, não é nem uma vacina, nem, muito menos, um sapo. Trata-se de fato de uma rã, conhecida como $R \tilde{a}$ Kambo, Rã-Kambô, Rã-Cambô ou Sapo-Verde. Denominada científicamente de Phyllomedusa bicolor, é a maior espécie do gênero da família Hylidae, que ocorre na Amazônia, podendo ser encontrado em quase todos países amazônicos, como as Guianas, Venezuela, Colômbia, Peru, Bolívia e Brasil (SOUZA, 2003, p.56-57).

A vacina do sapo é uma prática xamânica ou etnomedicinal de povos indígenas e comunidades tradicionais da Amazônia. A finalidade principal é tirar a panema, ou seja, afastar a má sorte na caça e com as mulheres. "Tradicionalmente usada como revigorante e estimulante para caça por grupos indígenas do sudoeste amazônico (entre eles, Katukina, Yawanawá e Kaxinawá) [...]" (LIMA; LABATE, 2007, p.90).

Revista de Direito Ambiental e Socioambientalismo | e-ISSN: 2525-9628 | Porto Alegre | v. 4 | n. 2

p. $01-18$ | Jul/Dez. 2018 
A vacina do sapo, como dito anteriormente, não é uma vacina, mas uma prática etnomedicinal onde a secreção cutânea da Rã-Kambô é aplicada "[...] queimando superficialmente a pele com um instrumento pontiagudo (cipó titica, entre os índios) e, em seguida, depositando na queimadura (chamada de 'ponto') a secreção do kambô - parcialmente diluída em água para desfazer a cristalização" (LIMA; LABATE, 2007, p.85).

Acontece que este conhecimento tradicional de indígenas foi indevidamente apropriado, através de patentes, pelos países do norte sociológico, que buscam se apropriar da biodiversidade e dos conhecimentos tradicionais associados amazônicos. Até janeiro de 2017, havia 18 (dezoito) pedidos de patentes de produtos relativos à Rã-Kambô. Dos cessionários destas patentes, “[...] mais de três quintos das patentes são requeridas pelos Estados Unidos da América, seguidos pelo Canadá com um quinto de todos os pedidos. Já o quinto restante está dividido entre os países da Europa, Japão e China [...]" (MIRANDA, 2018a, p. 198), o que configura claramente mais um caso de colonialismo biocultural.

Portanto, a falta de regulamentação interna no país, juntamente com o modo derivado de nascimento do Estado brasileiro, e da maioria dos países megadiversos, ou seja, a partir de uma colonização de exploração, bem como o tratamento do bem ambiental como um res nullius, juntamente com o domínio dos países do norte das tecnologias de bioprospecção e engenharia genética, criaram um cenário propício para o colonialismo biocultural do sul sociológico. Até que um caso envolvendo a Bioamazônia, Associação Brasileira para o Uso Sustentável da Biodiversidade da Amazônia, e a Novartis Pharma, multinacional farmacêutica de origem suíça, que assinaram um contrato que dava à Novartis direitos de acesso e uso exclusivos de material genético da região amazônica, alertou o três Poderes nacionais (MIRANDA, 2018b, p. 29).

Assim, em meados do ano 2000, foi editada uma norma específica com a pretensão de garantir a soberania do Estado sobre os recursos genéticos. Desta forma, foi editada a Medida Provisória $\mathrm{n}^{\mathrm{0}} 2.052$, de 29 de junho de 2000, que derivou, após sucessivas reedições, na Medida Provisória $\mathrm{n}^{\mathrm{o}} 2.186-16$, de 23 de agosto de 2001, que, por fim, foi revogada pela Lei $\mathrm{n}^{\mathrm{o}} 13.123$, de 20 de maio de 2015, que encontra-se vigente até momomento.

Portanto, atualmente, no Brasil o acesso aos conhecimentos tradicionais pode se dar de forma lícita, conforme a Lei no 13.123/15, ou ilicitamente, como descrito acima. Contudo, ambos os casos podem configurar o colonialismo biocultural. Isto porque, todo ou parte dos seres vivos, excetuando os microorganismos transgênicos, não podem ser patenteados, 


\section{A APROPRIAÇÃO INDEVIDA DO JAMBU (Acmella oleracea) E AS \\ INCONVENCIONALIDADES DO MARCO LEGAL DA BIODIVERSIDADE NO PROCESSO DE \\ COLONIALISMO BIOCULTURAL}

conforme, o artigo 18 da Lei de Propriedade Industrial. Ora, então se repete a questão: como ocorre a colonização biocultural?

Recapitulando, os conhecimentos tradicionais associados e a biodiversidade são indissociáveis, por isso a maior parte dos princípios ativos farmacológicos são descobertos a partir destes etnoconhecimentos. Além disso, as industrias multinacionais do norte utilizam as espécimes da biodiversidade e os conhecimentos tradicionais de países megadiversos do sul para isolarem os princípios ativos que lhes interessam, os quais são patenteados. Mas como pode haver patente se os seres vivos ou partes destes não são passíveis de patentes?

Isto ocorre porque a engenharia genética rompe com as axiologias culturais, religiosos e socioambientais que ligam a vida a terra, separando os fragmentos genéticos do ser vivo, negando a natureza viva deste, como argumento para sua coisificação, mercantilização e monopolização da biodiversidade e dos conhecimentos tradicionais associados (SANTOS, 1996, p.23-24).

Portanto, se o ser vivo ou parte dele não pode ser patenteado, como pode uma indústria multinacional ter uma patente de um medicamento produzido a partir de plantas, animais ou microrganismos da biodiversidade brasileira? A patente é do princípio ativo que produz o remédio, contudo este princípio ativo é composto de gens e moléculas do ser vivo em questão. Ora, isto não é parte do ser vivo? Claro que sim! Partes genéticas e moleculares de um ser vivo são patenteadas, não obstante a Lei de Propriedade Industrial, no Brasil, a Convenção sobre Diversidade Biológica, internacionalmente, entre outras normas, proíbam.

Esta é a grande falácia científica do século XXI que instrumentaliza a colonização biocultural, tanto através da engenharia genética, quanto da propriedade industrial. "Primeiro a ciência e a tecnologia desterritorializam as formas de vida, reduzindo-as a meros fragmentos genéticos; depois as grandes corporações, de posse desses fragmentos, transformam-os por sua vez em mercadoria especializada" (SANTOS, 1996, p.23-24). Ou seja, este produto, feito da parte genética de um ser vivo, é patenteado, criando-se assim, um monopólio, ainda que com termo determinado, da utilidade deste elemento da diversidade biológica.

\section{O COLONIALISMO BIOCULTURAL DO JAMBU}

Para exemplificar o colonialismo biocultural este trabalho examinou o caso do Jambu (Acmella oleracea), uma hortaliça tradicionalmente utilizada na gastronomia paraense e da região amazônica. Vale resaltar que esta planta faz parte dos conhecimentos tradicionais de

Revista de Direito Ambiental e Socioambientalismo | e-ISSN: 2525-9628 | Porto Alegre | v. 4 | n. 2

p. $01-18$ | Jul/Dez. 2018 
povos indígenas e comunidades tradicionais da Amazônia, que a utilizam, por diversas gerações, como analgésico, anestésico, fungicida e carrapaticida (FAPESP, 2018, p. 72).

Para demonstra isso, foi construída uma base de dados sobre patentes que se referiam ao Jambu (Acmella oleracea) até 05 de setembro de 2018. Para tanto, foi utilizado o método de análise de conteúdo, que constitui "um conjunto de técnicas de análise das comunicações visando obter por procedimentos sistemáticos e objectivos de descrição do conteúdo das mensagens indicadores [...]"(BARDIN, 1979, p. 44), que podem ser qualitativas ou quantitativas, “[...] que permitam a inferência de conhecimentos relativos às condições de produção/recepção (variáveis inferidas) destas mensagens. (BARDIN, 1979, p. 44). Desta forma, partiu-se da palavra-chave Acmella oleracea digitada no banco de dados do Instituto do Google Patentes. A escolha pelo mecanismo de busca Google foi feita uma vez que este indexa mais de 87 milhões de patentes e pedidos de patentes com texto completo de 17 escritórios de patentes, incluindo: Organização Mundial de Propriedade Intelectual (OMPI); Escritório de Patentes e Marcas dos Estados Unidos (USPTO); Escritório Europeu de Patentes (OEP); Escritório Estadual de Propriedade Intelectual da China (SIPO); Escritório de Patentes do Japão (JPO); Escritório Coreano de Propriedade Intelectual (KIPO); Escritório de Patentes e Marcas da Alemanha (DPMA); Escritório Canadense de Propriedade Intelectual (CIPO); bem como órgãos de propriedade intelectual da Rússia, Reino Unido, França, Espanha, Bélgica, Dinamarca, Finlândia, Luxemburgo e Países Baixos.

Da análise dos dados, foram elencados 304 (trezentos e quatro) pedidos e concessões de patentes de produtos relativos ao Jambu (Acmella oleracea), até 05 de setembro de 2018. Disto se percebeu que os três maiores cessionários, com mais de $80 \%$ (oitenta por cento), são do Japão, Estados Unidos da América e França, os quais correspondem, respectivamente, a $33,06 \%, 28,85 \%$ e $18,58 \%$ dos pedidos e concessões de patentes.

Em estudo parecido, porém com algumas diferenças metodológicas, é possível constatar uma realidade semelhante em números percentuais, embora haja uma diferença nos resultados absolutos. De acordo com o Instituto Nacional de Propriedade Industrial (INPI), existem 433 pedidos e concessões de patentes relacionados ao Jambu. Destas, “o Japão possui 137 solicitações e patentes concedidas referentes a planta, equivale a 32,16\%. Logo após os EUA apresenta 102 pedidos e patentes (23.94\%), França com 55 (12,91\%), Espanha $36(8,45 \%)$ e China 26 (6,10\%)” (INPI apud GUIMARÃES, 2018). Já no Brasil foram registrados “[...] 15 


\section{A APROPRIAÇÃO INDEVIDA DO JAMBU (Acmella oleracea) E AS \\ INCONVENCIONALIDADES DO MARCO LEGAL DA BIODIVERSIDADE NO PROCESSO DE \\ COLONIALISMO BIOCULTURAL}

patentes e pedidos [...] um percentual de 3,52\%, atrás da Alemanha com 10 pedidos e patentes $(2,35 \%)$ e Grã-Bretanha com sete (1,64\%)" (INPI apud GUIMARÃES, 2018).

Desta forma, é visível que as cessionárias de patentes do jambu (Acmella oleracea) são instituições de pesquisa e empresas de países desenvolvidos do norte sociológico, notadamente do Japão, Estados Unidos da América, e França, com quatro quintos dos pedidos de patentes.

Portanto, percebe-se que, apesar de terem sido obtidas por países do norte sociológico, estas patentes “[...] só foram possíveis por meio da apropriação de uma prática indígena milenarmente usada por comunidades tradicionais da região amazônica" (FERES; MOREIRA, 2014, p.27). Ora, um pesquisador, em um laboratório japonês, estadunidenses, francês, chinês, ou de qualquer outro lugar do planeta, só teve a ideia de extrair um peptídeo, um aminoácido, um gen ou outra molécula qualquer de uma planta amazônica, no caso da Acmella oleracea, por ter tido a informação de que povos indígenas e comunidades tradicionais da Amazônia faziam fins culinários, medicinais e xamânicos desta planta. Além disso, teve que obter espécimes deste vegetal da biodiversidade amazônica para realizar suas pesquisas.

Este é apenas um dos muitos casos de biocolonialismo que ameaçam a biodiversidade e os etnoconhecimentos dos países do sul. "Como o conhecimento tradicional constitui a biodiversidade, o desrespeito a esses conhecimentos, por meio do patenteamento dessas práticas tradicionais [...]" (FERES; MOREIRA, 2014, p.31), põe em risco a própria diversidade biológica. Isto ocorre em função da lógica mercantilista e monopolista do sistema de tutela da propriedade industrial no mundo. Assim, os países do norte fomentam esta lógica de mercado para a pseudoproteção à biodiversidade e aos conhecimentos tradicionais.

Portanto, o velho, assim como o novo, colonialismo são frutos das exigências do mercado. Outrora do mercantilismo, contemporaneamente da sociedade de consumo pósmoderna. Desta forma, ao longo da história do capitalismo é possível observar como a vida foi moldada às exigências do mercado capitalista, de tal forma que introjetou a racionalidade do capital no interior das sociedades ocidentais, influenciando também outras culturas e os modos de vida. Assim, o capitalismo desenvolveu diferentes formas de colonialismo e imperialismo, impondo a visão do capital como a única forma de ver, entender e agir no mundo (RUBIO; ALFARO, 2003, p.46).

Neste sentido comenta Joaquim Herrera Flores (2008, p.47):

Revista de Direito Ambiental e Socioambientalismo | e-ISSN: 2525-9628 | Porto Alegre | v. 4 | n. 2

p. $01-18$ | Jul/Dez. 2018 
Da mesma maneira, agora de um ponto de vista externo, as diferentes formas de colonialismo e imperialismo funcional para tais relações sociais dominadas pelo capital tem sido generalizada desta forma particular e peculiar de lidar com a vida como se fosse a única maneira de ver, compreender e agir no mundo. (Tradução nossa).

Esta visão mono cognitiva leva à eliminação das pluralidades e diferenças culturais, que, nesta ótica, são impedimentos e obstáculos para a expansão do capital. Desta maneira, o mercado, como uma mão invisível, busca controlar tudo, das matérias-primas aos mercados, passando pela cultura e biodiversidade, em um processo denominado nesta tese de colonialismo biocultural.

Desta forma, o capital utiliza como estratégia o combate à diversidade, apostando na uniformização de culturas. Para tanto, a arma utilizada é a força, travestida de livre mercado. Assim, a violência gerada neste processo de uniformização e homogeneização das culturas leva a criação de monopólios sobre a vida e os recursos vivos, como no caso citado do jambu, que se manifestam em múltiplos níveis, como o político, o ecológico e o sociocultural.

A violência política se dá mediante o uso da força, do controle e da centralização, afastando-se da democracia de fato, embora formalmente esta continue. Já a violência ecológica, tem duas vertentes. A primeira ocorre através da violência às diversas espécies da natureza, incluindo a extinção e patenteamento da biodiversidade. A segunda vertente se dá pelo controle da produção mediante monocultivos que geram uma grande desestabilização ecológica e erosão genética. Por fim, a violência sociocultural se manifesta na agressão e na fragmentação de sistemas sociais e culturais diversos para integrá-los em um sistema global, padronizado e homogêneo, considerado como o único válido (RUBIO; ALFARO, 2003, p.47).

Neste sentido, os princípios axiológicos que imperam na pós-modernidade implicam em uma hegemonia e uma pretensão de apropriação exclusiva dos conhecimentos tradicionais associados à biodiversidade, e, consequentemente, na redução da diversidade biológica e na monopolização destes recursos ambientais. Tal processo ocorre mediante as constantes modificações nos institutos da propriedade industrial, visando ampliar cada vez mais o espectro de patenteamento da vida.

Neste sentido, a lei Internacional de Propriedade Intelectual exige cada vez mais a patenteabilidade de material genético. Não é por acaso que nesta investigação foi levantada mais de 300 (trezentas) patentes do jambu. Não obstante, várias organizações não governamentais e os países megadiversos têm se oposto a esta extensão da lei de patentes, reivindicando novos direitos de propriedade sobre recursos genéticos e conhecimentos

Revista de Direito Ambiental e Socioambientalismo | e-ISSN: 2525-9628 | Porto Alegre | v. 4 | n. 2 | 


\section{A APROPRIAÇÃO INDEVIDA DO JAMBU (Acmella oleracea) E AS \\ INCONVENCIONALIDADES DO MARCO LEGAL DA BIODIVERSIDADE NO PROCESSO DE \\ COLONIALISMO BIOCULTURAL}

tradicionais (MORIN, 2004), a lógica monopolista e biocolonialista tem prevalecido, como pode ser visto no caso do jambu e diversos outros.

\section{A INCONVENCIONAL LEGITIMAÇÃO DO COLONIALISMO BIOCULTURAL DOS CONHECIMENTOS TRADICIONAIS ASSOCIADOS À BIODIVERSIDADE}

A Lei 13.123/2015, bem como seu decreto regulamentador, apregoada pelo governo brasileiro como o novo marco legal da biodiversidade, configuram uma tentativa, inconvencional, de legitimar este colonialismo biocultural pelo Estado brasileiro, certamente fomentado por interesses internacionais, através do lobby no Congresso Nacional, em detrimento dos povos indígenas, comunidades tradicionais e da sociedade brasileira em geral.

O que ocorre é que a Convenção sobre Diversidade Biológica prevê um sistema de acesso aos conhecimentos tradicionais associados ao patrimônio genético, com uma respectiva repartição de benefícios. Ademais a Convenção $\mathrm{n}^{\mathrm{o}} 169$ da OIT prevê a necessidade de que seja realizada uma consulta prévia, livre e informada, sempre que sejam previstas medidas administrativas ou legislativas que afetem diretamente este povos.

Assim, um dos principais direitos dos Povos e Comunidades Tradicionais é o direito à consulta prévia, ao qual está vinculado o direito ao consentimento prévio informado (ou fundamentado). Tal direito é assegurado como um dos direitos estruturantes dos direitos humanos dos povos e comunidades tradicionais e encontram na Convenção $\mathrm{n}^{\circ} 169$ da Organização Internacional do Trabalho (OIT), promulgada no Brasil pelo Decreto ${ }^{\circ}$ 5.051, de 19 de abril de 2004, sua principal norma internacional. Este direito é previsto na convenção nos seguintes termos:

\section{ARTIGO 6 ${ }^{\circ}$}

1. Na aplicação das disposições da presente Convenção, os governos deverão:

a) consultar os povos interessados, por meio de procedimentos adequados e, em particular, de suas instituições representativas, sempre que sejam previstas medidas legislativas ou administrativas suscetíveis de afetá-los diretamente; [...] (OIT, 2001, p.18).

Este direito é reiterado na Declaração de Direitos Indígenas da ONU:

Artigo 32

$[\ldots]$

2. Os Estados celebrarão consultas e cooperarão de boa fé com os povos indígenas interessados, por meio de suas próprias instituições representativas, a fim de obter seu consentimento livre e informado antes de aprovar qualquer projeto que afete suas terras ou territórios e outros recursos, particularmente em relação ao desenvolvimento, à utilização ou à exploração de recursos minerais, hídricos ou de outro tipo. [...] (ONU, 2008, p.16-17).

Revista de Direito Ambiental e Socioambientalismo | e-ISSN: 2525-9628 | Porto Alegre | v. 4 | n. 2 |

p. $01-18$ | Jul/Dez. 2018 
Assim, este direito deve se constituir no centro de gravidade em torno do qual gira o sistema de acesso e uso criado pela Convenção sobre Diversidade Biológica (CDB). A CDB dispõe que o consentimento prévio fundamentado das comunidades indígenas e locais deve ser obtido com relação aos conhecimentos, inovações e práticas das comunidades locais e populações indígenas, que, de acordo com o Art. 8, j, da CDB, devem ser respeitadas, preservadas e mantidas "[...] com estilo de vida tradicionais relevantes à conservação e à utilização sustentável da diversidade biológica e incentivar sua mais ampla aplicação com a aprovação e a participação dos detentores desse conhecimento, inovações e práticas [...]" (MMA, 2000, p.11-12).

Entretanto, o dito marco legal da biodiversidade estabeleceu um verdadeiro cipoal de isenções para o consentimento prévio fundamentado e para a repartição de benefícios. Uma das mais graves é a isenção para acesso e uso dos conhecimentos tradicionais relacionados à agrobiodiversidade $^{\dagger}\left(\mathrm{FAO}, 2005\right.$, p.3) que estão em rota de colisão com a Convenção $\mathrm{n}^{\circ} 169$ da OIT e a CDB, como será visto mais adiante.

Analisando o marco legal da biodiversidade é possível evidenciar tais absurdos legislativos. Neste tocante, $\mathrm{o}$ art. $2^{\circ}$, da Lei 13.123/15, em seu inciso VI, definiu o consentimento prévio informado como aquele "consentimento formal, previamente concedido por população indígena ou comunidade tradicional segundo os seus usos, costumes e tradições ou protocolos comunitários" (BRASIL, 2015).

Todavia, esta mesma norma estabeleceu hipóteses de isenção da obrigatoriedade de obtenção deste consentimento criando regras diferenciadas de consentimento, e estabelecendo verdadeiras subcategorias de conhecimentos tradicionais, o que por si já é uma prática discriminatória, ao pressupor que existem conhecimentos tradicionais mais importantes e outros de menor importância, ou mesmo que para uns existe direito e para outros, sem qualquer fundamento este direito é deixado de lado.

Desta maneira, foi estabelecida na lei uma distorcida subdivisão de conhecimentos tradicionais: conhecimento tradicional associado de origem identificável; e conhecimento tradicional associado de origem não identificável.

O conhecimento tradicional de origem identificável fora conceituado como “[...] informação ou prática de população indígena, comunidade tradicional ou agricultor tradicional sobre as propriedades ou usos diretos ou indiretos associada ao patrimônio genético [...]" (BRASIL, 2015), conforme inciso II, do Art. $2^{\circ}$. Já o conhecimento tradicional de origem não identificável seria, nos termos da lei, o "[...] conhecimento tradicional associado em que não há a possibilidade de vincular a sua origem a, pelo menos, uma população indígena, comunidade tradicional ou agricultor tradicional [...]" (BRASIL, 2015), de acordo com o inciso III, do Art. $2^{\circ}$. Assim, para esta subcategoria o legislador isentou o acessante da obrigatoriedade de obtenção do consentimento prévio para seu acesso. Diante disso surgem os seguintes questionamentos: as práticas etnomedicinais que utilizam o jambu seriam consideradas conhecimentos tradicionais de origem identificável ou não identificável? Se não identificáveis, não mereceriam a proteção da consulta livre, prévia e informada?

\footnotetext{
† Agrobiodiversidade configura a variedade e diversificação dos animais, plantas e microorganismos utilizados directamente ou indirectamente para alimentação e agricultura, incluindo colheitas, gado, silvicultura e pesca. Inclui a diversidade dos recursos genéticos (variedades, raças) e espécies utilizados para a alimentação, forragem, fibra, combustível e fins terapêuticos. Inclui também a diversidade das espécies não colhidas que apoiam a produção (microorganismos terrestres, predadores, polinizadores) e os do ambiente mais vasto que apoia os ecossistemas agrícolas (agrícolas, pastorais, florestais e aquáticos), assim como a diversidade dos próprios ecossistemas agrícolas.
}

Revista de Direito Ambiental e Socioambientalismo | e-ISSN: 2525-9628 | Porto Alegre | v. 4 | n. 2 |

p. $01-18$ | Jul/Dez. 2018 


\section{A APROPRIAÇÃO INDEVIDA DO JAMBU (Acmella oleracea) E AS INCONVENCIONALIDADES DO MARCO LEGAL DA BIODIVERSIDADE NO PROCESSO DE COLONIALISMO BIOCULTURAL}

Prosseguindo numa escalada de absurdos, o $\S 3^{\circ}$, do Art. $9^{\circ}$, da Lei 13.123/15, considerou que o acesso à uma parcela da agrobiodiversidade teria tratamento equivalente ao destinado ao conhecimento tradicional de origem não identificável, quais sejam os conhecimentos tradicionais associados ao patrimônio genético de variedade vegetal tradicional local ou crioula ou à raça animal localmente adaptada ou crioula para atividades agrícolas corresponde ao acesso de conhecimento tradicional associado não identificável que deu origem à variedade ou à raça, criando uma injustificada e desigual isenção da obrigatoriedade de consentimento das comunidades tradicionais quando o conhecimento tradicional estiver associado à estes bens. Assim emergem outros questionamentos: o jambu seria uma variedade vegetal tradicional local ou crioula para atividades agrícolas? Em sendo, seu uso medicinal pelas comunidades tradicionais seria considerado conhecimento tradicional associado ao patrimônio genético de variedade vegetal tradicional, sendo corresponde ao acesso de conhecimento tradicional associado não identificável? Tal situação, gerada pelo marco legal da biodiversidade, seria uma afronta às diversas convenções internacionais e ao próprio texto constitucional.

Para além da ruptura com a lógica da obrigatoriedade estruturante da consulta prévia, a isenção estabelecida pelo legislador vulnera gravemente a agrobiodiversidade e por consequência a soberania alimentar destes povos.

Assim, de acordo com o inciso XXXII, do Art. $2^{\circ}$, da Lei 13.123/15, a variedade tradicional local ou crioula, seria uma variedade vegetal, que não seja substancialmente semelhante a cultivares comerciais, proveniente de espécie que ocorre na natureza ou mantida em condição ex situ, desenvolvida, incluindo a combinação de seleção natural e humana, ou adaptada por população indígena, comunidade tradicional ou agricultor tradicional.

Já o inciso seguinte, define a raça localmente adaptada ou crioula como aquela proveniente de espécie animais encontradas na natureza ou mantida em condição ex situ, " [...] desenvolvida ou adaptada a um determinado nicho ecológico e formada a partir de seleção natural ou seleção realizada adaptada por população indígena, comunidade tradicional ou agricultor tradicional" (BRASIL, 2015), isto é "[...] que utiliza variedades tradicionais locais ou crioulas ou raças localmente adaptadas ou crioulas e mantém e conserva a diversidade genética, incluído o agricultor familiar" (BRASIL, 2015).

Portanto, a Lei 13.123/15 apenas condiciona à obtenção de consentimento prévio informado o acesso ao conhecimento tradicional associado de origem identificável, dispensando o consentimento prévio para o conhecimento tradicional associado de origem não identificável e para o acesso ao patrimônio genético para atividades agrícolas de variedade ou raça tradicional, crioula ou localmente adaptada em total violação ao direito à consulta prévia assegurado no arcabouço jurídico internacional que protege este direito humanos.

Desta forma, o jambu, em uma interpretação literal da lei, poderia ser considerada uma espécie crioula da agrobiodiversidade. Se assim fosse considerada, o acesso ao conhecimento tradicional que envolve este hortaliça, estaria isenta de consentimento prévio.

Portanto o marco legal da biodiversidade configura a inconvencional legitimação do colonialismo biocultural. Entretanto, como a Lei $\mathrm{n}^{\circ} 13.123 / 15$ entra em conflito com a Convenção sobre Diversidade Biológica e a Convenção $\mathrm{n}^{\circ} 169$ da OIT, esta norma é inconvencional, não podendo prevalecer, como será demonstrado a seguir.

Assim, a incompatibilidade da referida lei perante as convenções internacionais de direitos humanos, em especial a Convenção 169 da OIT caracteriza a inconvencionalidade e inaplicabilidade da norma interna no que tange aos pontos que visam a supressão de direitos assegurados pela convenção. Ademais, a total ausência de consulta prévia aos povos e

Revista de Direito Ambiental e Socioambientalismo | e-ISSN: 2525-9628 | Porto Alegre | v. 4 | n. 2 |

p. $01-18$ | Jul/Dez. 2018 
comunidades tradicionais no processo legislativo da Lei $13.123 / 15$, por si caracteriza também a inconvencionalidade do referido dispositivo legal, que está totalmente viciado frente ao princípio da consulta prévia da Convenção $n^{\circ} 169$ da OIT, bem como da Convenção sobre Diversidade Biológica (CDB), comentado anteriormente.

Por esta razão, os $\S \S 2^{\circ}$ e $3^{\circ}$, do artigo $9^{\circ}$, da Lei $13.123 / 15$ são inaplicáveis em razão da sua incompatibilidade com os artigos $6^{\circ}$ da Convenção n ${ }^{\circ} 169$ da OIT e $8^{\circ}$ e 15 da $\mathrm{CDB}$, os quais, por serem tratados de direitos humanos possuem status supralegal, conforme jurisprudência do Supremo Tribunal Federal (STF, 2009). Neste sentido, comenta o Professor Valério de Oliveira Mazzuoli que "[...] a produção normativa doméstica conta com um duplo limite vertical material: a) a Constituição e os tratados de direitos humanos ( $1^{\circ}$ limite $)$ e b) os tratados internacionais comuns ( $2^{\circ}$ limite $)$ em vigor no país" $(2009$, p.137).

Entretanto, o entendimento do STF é que apenas os tratados de direitos humanos aprovados com o quórum qualificado do $\S 3^{\circ}$, do art. $5^{\circ}$, do texto constitucional, possuem status constitucional. Portanto, os demais tratados de direitos humanos, aprovados sem a maioria qualificada, possuiriam natureza supra legal, o que torna "[...] inaplicável a legislação infraconstitucional com ele conflitante, seja ela anterior ou posterior ao ato de adesão" (STF, 2009), caracterizando assim a inconvencionalidade das leis que se opõem aos tratados internacionais de direitos humanos. Neste sentido, o Professor Antonio Moreira Maués lembrou que antes de 1988 " [...] o STF havia firmado o entendimento, no julgamento do RE n $^{\circ} 80.004$ (J. 01/06/1977) de que os tratados internacionais incorporam-se ao direito interno no mesmo nível das leis, podendo ser revogados por lei posterior ou deixar de ser aplicados em favor de lei específica” (MAUES, 2004, p.217), mas que em dezembro de 2008 “[...] a posição adotada pela maioria do STF, no entanto, foi a tese da supralegalidade (MAUES, 2004, p.218).

Por esta razão, o só fato do processo legislativo da Lei 13.123/15 não ter garantindo a consulta prévia aos povos e comunidades tradicionais já seria suficiente para declarar a inconvencionalidade da referida lei. Entretanto, ainda existem mais incongruências entre esta lei e outros tratados de direitos humanos, frente ao acesso à biodiversidade e agrobiodiversidade e aos conhecimentos tradicionais o que é assunto para um outro trabalho.

Conforme comentado anteriormente, a Lei 13.123/15 condiciona o acesso ao conhecimento tradicional associado de origem identificável à obtenção de consentimento prévio informado, porém isenta de consulta o acesso ao conhecimento tradicional associado de origem não identificável. Ademais, considera que o acesso ao conhecimento tradicional associado ao patrimônio genético de variedade tradicional e raça crioula ou localmente adaptada corresponde ao acesso de conhecimento tradicional associado não identificável, isentando, também, de consulta prévia. Desta forma, as isenções da consulta para o acesso à agrobiodiversidade crioula ou localmente adaptada e aos conhecimentos tradicionais associados a esta, conflitam flagrantemente com a Convenção $n^{\circ} 169$ da OIT e com a Convenção sobre Diversidade Biológica (CDB).

Neste sentido, diante das antinomias entre normas externas e internas, as leis brasileiras estão sujeitas a dois tipos de controle vertical: de constitucionalidade; e de convencionalidade, como comentado anteriormente. Contudo, nem tudo que é recebido pela Constituição é convencional e válido, porque agora as leis devem também ter compatibilidade com as Convenções internacionais. Portanto, uma lei pode ser constitucional, mas, ao mesmo tempo, inconvencional (GOMES, 2011). Assim, tanto no caso de inconstitucionalidade como na hipótese de inconvencionalidade, a lei perde sua validade, como ocorre com a Lei 13.123/15.

Um exemplo ampliado é a decisão da Corte Interamericana de Direitos Humanos (CIDH) no caso Gomes Lund (Guerrilha do Araguaia) versus Brasil (CIDH, 2010), no qual

Revista de Direito Ambiental e Socioambientalismo | e-ISSN: 2525-9628 | Porto Alegre | v. 4 | n. 2 |

p. $01-18$ | Jul/Dez. 2018 


\section{A APROPRIAÇÃO INDEVIDA DO JAMBU (Acmella oleracea) E AS \\ INCONVENCIONALIDADES DO MARCO LEGAL DA BIODIVERSIDADE NO PROCESSO DE \\ COLONIALISMO BIOCULTURAL}

entende que "[...] as leis de anistia (no Brasil, trata-se da Lei n. ${ }^{\circ}$ 6.683/79) são inválidas (não obstante vigentes) em relação aos atos desumanos, generalizados ou sistemáticos, praticados contra a população civil, durante a ditadura militar, pelos agentes públicos ou [...] com conhecimento desses agentes" (GOMES, 2011). Isto demonstra a aplicação da inconvencionalidade das leis pelo $\mathrm{CIDH}$ diante de violações aos tratados internacionais de Direitos Humanos.

Desta forma, a partir de então impera a obrigatoriedade de que todos os agentes públicos observem o controle de convencionalidade, uma vez que a Convenção Americana de Direitos Humanos "[...] equivale a uma Constituição supranacional atinente a Direitos Humanos" (CIDH, 2010). Portanto, todas as esferas nacionais e os poderes públicos e, portanto, seus agentes, bem como as respectivas legislações federais, estaduais e municipais de todos os Estados aderentes estão obrigados a respeitá-la e a ela se adequar (CIDH, 2010).

Ante o exposto, perante estas inconvencionalidades e da inaplicabilidade da Lei $\mathrm{n}^{\mathrm{o}}$ 13.123/15 nestes aspectos comentados, fica claro a inafastabilidade da consulta prévia, livre e informada para qualquer caso, inclusive para o acesso à agrobiodiversidade crioula ou localmente adaptada e aos conhecimentos tradicionais associados, como no caso do jambu, por exemplo.

\section{CONCLUSÃO}

Diante do exposto, fica patente a existência de um processo em curso para apropriação da biodiversidade e dos conhecimentos tradicionais associados, chamado neste trabalho de colonialismo biocultural. Assim, os avanços da engenharia genética desterritorializam a vida e se apropriam desta, gerando sérios impactos socioambientais, erosão genética e até podendo levar a extinção de espécies e culturas.

Apesar das nefastas consequências deste colonialismo biocultural há dois movimentos antagônicos em curso. Por um lado, fundado no capital e interesses de corporações multinacionais farmacológicas e agroquímicas, procura-se legitimar no mundo esta apropriação através da propriedade intelectual. Por outra, povos indígenas, comunidades tradicionais, militantes de Direitos Humanos, entre outros, resistem bravamente, porém ingloriamente, às forças econômicas que fomentam o colonialismo biocultural.

No Brasil, este processo de legitimação foi instrumentalizado pela Lei no 13.123/15, que, entre outras coisas, dispõe sobre o acesso ao patrimônio genético, sobre a proteção e o acesso ao conhecimento tradicional associado e sobre a repartição de benefícios para conservação e uso sustentável da biodiversidade. Acontece que esta norma colide com a Convenção sobre Diversidade Biológica e a Convenção nº 169 da OIT. Diante disso, tal legitimação é inconvencional, não podendo prosperar.

Revista de Direito Ambiental e Socioambientalismo | e-ISSN: 2525-9628 | Porto Alegre | v. 4 | n. 2 |

p. $01-18$ | Jul/Dez. 2018 
Isto porque, pela Convenção Americana de Direitos Humanos, os Estados possuem a obrigação de adotar medidas para eliminar normas legais e práticas de quaisquer espécies que violem a Convenção. Além disso, os Estados também possuem o compromisso de editar leis e desenvolverem ações que conduzam ao respeito mais amplo e efetivo da Convenção. De igual forma, as Constituições nacionais devem ser interpretadas ou, se necessário, até emendadas para manter harmonia com a Convenção e com a jurisprudência da Corte Interamericana de Direitos Humanos.

Portanto, tais incongruências configuram inconvencionalidades e inconstitucionalidades do marco legal da biodiversidade. Consequentemente acarreta a inaplicabilidade desta legislação infraconstitucional conflitante com tratados de direitos humanos, seja ela anterior ou posterior ao ato de adesão, devido ao caráter supra legal dos tratados jushumanistas. Assim, os processos de patenteamento do jambu (Acmella oleracea) representam uma apropriação ilícita da biodiversidade brasileira, que não pode prosperar.

\section{REFERÊNCIAS}

AZEVEDO, Cristina Maria do Amaral; MOREIRA, Teresa Cristina. A proteção dos conhecimentos tradicionais associados: Desafios a enfrentar. Revista do patrimônio histórico e artístico nacional, Brasília, DF, IPHAN, $\mathrm{n}^{\circ}$ 32, p.44-61, 2005.

BARDIN, Laurence. Análise de conteúdo. Lisboa: Ed. 70, 1979.

BAUMAN, Zygmunt. Modernidade líquida. Tradução de Plínio Dentzien. Rio de Janeiro: Zahar, 2003.

BOURDIUE, Pierre. Poder, derecho y clases socials. 2. ed. Bilbao, ES: Desclee de Brouwer, 2001.

BRASIL. Lei n ${ }^{\circ}$ 13.123, de 20 de maio de 2015. Diário Oficial da União, Poder Executivo, Brasília, DF, 14 maio 2015.

BRASIL. Supremo Tribunal Federal. RE. 349703/RS. Rel. Min. Carlos Britto. Rel. Acordão Min. Gilmar Mendes. Tribunal Pleno, julgamento em 03/12/08, DJe-104 de 05/06/09.

CIDH. Corte Interamericana de Direitos Humanos. Caso Gomes Lund e outros ("Guerrilha do Araguaia") Vs. $\quad$ Brasil, 24 nov. 2010.20 Disponível <file:///E:/DOUTORADO/TESE/material/CASO \%20GOMES\%20LUND\%20E\%20OUTROS\%20(\%E2\%80\%9 CGUERRILHA\%20DO\%20ARAGUAIA\%E2\%80\%9D)\%20VS.\%20BR ASIL.pdf >. Acesso em: 5 jun. 2016.

CRUTZEN, Paul J.; STEFFEN, Will; McNEILL, Jhon R.. The Anthropocene: Are Humans Now Overwhelming the Great Forces of Nature? Ambio, vol. 36, n. 8, dez. 2007.

CUNHA, Manuela Carneiro da; ALMEIDA, Mauro Barbosa de (orgs.). Enciclopédia da floresta: O alto juruá: Práticas e conhecimentos das populações. São Paulo: Companhia das Letras, 2002.

DERANI, Cristiane. Tutela jurídica da apropriação do meio ambiente e as três dimensões da propriedade. Hiléia: Revista de Direito Ambiental da Amazônia, Manaus, v. 1, n. ${ }^{\circ}$ 1, p. 61-84, 2003.

ESPERANDIO, Mary Rute Gomes. Para entender pós-modernidade. São Leopoldo: Sinodal, 2007.

FAO. Organização das Nações Unidas para a Alimentação e Agricultura. Manual de formação: interação do gênero, da agrobiodiversidade e dos conhecimentos locais ao serviço da segurança alimentar. Roma, Itália: FAO, 2005.

Revista de Direito Ambiental e Socioambientalismo | e-ISSN: 2525-9628 | Porto Alegre | v. 4 | n. 2 |

p. $01-18$ | Jul/Dez. 2018 


\section{A APROPRIAÇÃO INDEVIDA DO JAMBU (Acmella oleracea) E AS INCONVENCIONALIDADES DO MARCO LEGAL DA BIODIVERSIDADE NO PROCESSO DE COLONIALISMO BIOCULTURAL}

FAPESP. Planta eclética: O jambu, além da culinária, é utilizado em cosméticos e poderá ter uso na odontologia e como carrapaticida. Revista Pesquisa Fapesp. Edição no 263, jan., 2018. Disponível em: <http://revistapesquisa.fapesp.br/2018/01/16/planta-ecletica/>. Acesso em: 05 set. 2018.

FARIA, Caroline. Biopirataria. InfoEscola. Disponível em: $\langle$ http://www.infoescola.com/biologia/biopirataria/ $>$ Acesso em: 27 jan. 2017.

FERES, Marcos Vinício Chein; MOREIRA, João Vítor Freitas. Proteção jurídica da biodiversidade amazônica: o caso do conhecimento tradicional. Revista Direito Ambiental e sociedade, Caxias do Sul, RS, v. 4, nº 2, p.9-36, 2014.

FLORES, Joaquim Herrera. La reinvención de los Derechos Humanos. Andalucia, ES: Atrapasueños, 2008.

GOMES, Luiz Flávio. A lei da anistia viola convenções de direitos humanos. Consultor Jurídico, São Paulo, 10 mar. 2011. Disponível em: <http://www.conjur.com.br/2011-mar-10/coluna-lfg-lei-anistia-violaconvencoesdireitos-humanos\# ftnref2 4184>. Acesso em: 5 jun. 2016.

JACKSON, Joe. O ladrão no fim do mundo. Tradução de Saulo Adriano. Rio de Janeiro: Objetiva, 2011.

LAVORATO, Marilena Lino de Almeida. Biodiversidade um ativo de imenso valor: Biopirataria, plantas medicinais e etnoconhecimento. Itajaí, SC: UNIVALI: Projeto aves marinhas, [200?].

LIMA, Edilene Coffaci de; LABATE, Beatriz Caiuby. "Remédio da Ciência" e "Remédio da Alma": os usos da secreção do kambô (Phyllomedusa bicolor) nas cidades. CAMPOS: Revista de Antropologia Social, Curitiba, PR, v. $8, \quad \mathrm{n}^{\mathrm{o}} 1, \quad$ p.71-90, 2007. p.90. ISSN: 1519-5538. Disponível em: <file:///C:/Documents\%20and\%20Settings/Jo\%C3\%A3o\%20Paulo/Meus\%20documentos/Downloads/955329353-1-PB.pdf>. Acesso em: 28 jan. 2017.

MADRAZO, Alejandro Lajous. Biocolonialismo. In: SEMINARIO EN LATINOAMÉRICA DE TEORÍA CONSTITUCIONAL Y POLÍTICA, 2011, New Haven, Connecticut, EUA. Anais ... New Haven: Yale Law School, 2011

Maria Paula Meneses, Epistemologias do sul. Revista Crítica de Ciências Sociais, Coimbra, no 80, p.5-10, 2008.

MAUÉS, Antonio Moreira. Supralegalidade dos tratados internacionais de direitos humanos e interpretação constitucional. SUR - Revista Internacional de Direitos Humanos.São Paulo, Vol. 1, no 1, p.215-235, 2004.

MAZZUOLI, Valerio de Oliveira. O controle jurisdicional da convencionalidade das leis.São Paulo: Revista dos tribunais, 2009.

MIRANDA, João Paulo Rocha de; XAVIER, Alexandre Vientine. A tutela jurídica dos conhecimentos tradicionais associados à diversidade biológica e à agrobiodiversidade: segurança jurídica ou apropriação do patrimônio genético enquanto bem ambiental? In: SOUZA, Maria Cláudia da Silva Antunes de; FIORILLO, Celso Antonio Pacheco; YOSHIDA, Consuelo Yatsuda Moromizato. Direito ambiental II. Florianópolis: FUNJAB: CONPEDI, 2013. p.199. Disponível em: 〈http://www.publicadireito.com.br/artigos/?cod=4163634d39ec5b1d >. Acesso em: 20 jan 2017.

MIRANDA, João Paulo Rocha de Miranda. Biodiversidade brasileira: Aspectos jurídicos e socioambientais da sua apropriação. Barra do Garças, MT: João Paulo Rocha de Miranda: Pensar Direito: UFMT/CUA, 2014. ISBN 978-85-918416-0-8. Disponível em: <https://www.facebook.com/projetopensardireito/>. Acesso em: 07 set. 2018.

MIRANDA, João Paulo Rocha de. A inconvencional legitimação do colonialismo biocultural dos conhecimentos tradicionais associados à biodiversidade na era do antropoceno: um estudo a partir do caso da rã-kambo. In: LEITE, José Rubens Morato; FERREIRA, Heline Sivini (Orgs.). Direito e Sustentabilidade na Era do Antropoceno: Retrocesso Ambiental, Balanços e Perspectivas. Série Prêmio José Bonifácio de Andrada e Silva, Vol. 3, São Paulo: Instituto O direito por um planeta verde, 2018.

MIRANDA, João Paulo Rocha de Miranda. O marco legal da biodiversidade: proteção do patrimônio genético e dos reconhecimentos tradicionais associados e suas inconvencionalidades no contexto do colonialismo biocultural. São Paulo: Liber Ars, 2018.

MMA. Ministério do Meio Ambiente. Convenção sobre diversidade biológica. Brasília: MMA, 2000.

MORIN, Jean-Frédéric. Une réplique du Sud à l'extension du droit des brevets: la biodiversité dans le régime international de la propriété intellectuelle. Droit et Société, Paris, FR, n. 58, p. 633-653, 2004. Disponível em:

Revista de Direito Ambiental e Socioambientalismo | e-ISSN: 2525-9628 | Porto Alegre | v. 4 | n. 2 |

p. $01-18$ | Jul/Dez. 2018 
http://www.iddri.com/Publications/Publications-scientifiques-et-autres/Biodiversite dans regime DPI.pdf>. Acesso em: 23 jan. 2017.

OIT. Convenção $n^{\circ} 169$ sobre povos indígenas e tribais e Resolução referente à ação da OIT. Brasília-DF: OIT, 2011.

OLIVEIRA, Thiago Pires. Biocolonialismo: Um desafio para a efetivação do direito dos povos indígenas ao patrimônio genético. Revista de informação legislativa, Brasília, a.49, nº195, p.149-157, jul./set., 2012.

ONU. Declaração das Nações Unidas sobre os Direitos dos Povos Indígenas. Rio de Janeiro: ONU, 2008.

POSEY, Darrel A.. Etnoentomologia de tribos indígenas da Amazônia. In: RIBEIRO, Darcy; RIBEIRO, Berta Gleizer. (org.). Suma Etmológica Brasileira, vol. 1, Petrópolis: FINEP/Vozes, 1987.

RUBIO, David Sánchez; ALFARO, Norman J. Solórzano. Hiléia: Revista de Direito Ambiental da Amazônia, Manaus, v. 1, n. ${ }^{\circ}$ 1, p. 61-84, 2003.

SANTOS, Boaventira de Sousa. Epistemologias do sul. São Paulo: Cortez, 1995.

SANTOS, Boaventura de Sousa. Descolonizar el saber, reinventar el poder.Montivideo: Universidad de la República: Trilce, 2010.

SANTOS, Boaventura de Sousa. MENESES, Maria Paula. Epistemologias do sul. Revista Lusófona de Educação, Coimbra, PT, nº 13, p.183-189, 2009.

SANTOS, Boaventura de Souza. Do pós-moderno aos pós-colonial: e para além de um e outro. In: Congresso Luso-Afro-Brasileiro de Ciências Sociais, 8., 2004, Coimbra. Anais eletrônicos... Coimbra: Faculdade e Economia da Universidade de Coimbra, 2004. Disponível em: < http://www.ces.uc.pt/misc/Do_pos-moderno_ao_poscolonial.pdf >. Acesso em 17 jan. 2017.

SANTOS, Laymert Garcia dos. Propriedade intelectual ou direitos intelectuais coletivos? In: ARAÚJO, Ana Valéria; CAPOBIANCO, João Paulo (orgs). Biodiversidade e proteção do conhecimento de comunidades tradicionais. São Paulo: ISA, 1996.

SHIVA, Vandana. Biodiversidade, direitos de propriedade intelectual e globalização. In: SANTOS, Boaventura de Sousa (org.). Semear outras soluções: os caminhos da biodiversidade e dos conhecimentos rivais. Rio de Janeiro: Civilização Brasileira, 2005.

SHIVA, Vandana. Biopirataria: a pilhagem da natureza e do conhecimento. Tradução de Laura Cardellini Barbosa de Oliveira. Petrópolis, RJ: Vozes, 2001. ISBN 85-326-2508-8.

SOUZA, Moisés Barbosa. Diversidade de Anfíbios nas Unidades de Conservação Ambiental: Reserva Extrativista do Alto Juruá (REAJ) e Parque Nacional da Serra do Divisor (PNSD), Acre, Brasil. 2003, 279 f.. Tese (Doutorado em Ciências Biológicas). Instituto de Biociências, Universidade Estadual Paulista Júlio de Mesquita Filho, Rio Claro, SP, 2003.

WATERS, Colin N.; et. al. The Anthropocene is functionally and stratigraphically distinct from the Holocene. Science, vol. 351, jan. 2016.

ZOLNERKEVIC, Igor. A era humana. Pesquisa FAPESP, ed. 243, maio, 2016. Disponível em: $<$ http://revistapesquisa.fapesp.br/2016/05/19/a-era-humana/>. Acesso em: 18 mar. 2017. 